\title{
BAPTISAN ANAK DALAM PENGAKUAN IMAN WESTMINSTER DAN KATEKISMUS HEILDERBERG
}

\author{
Deniati $^{1)}$ Yesaya Adhi Widjaya ${ }^{2)}$ \\ 1) Universitas Pelita Harapan - Tangerang \\ E-mail: deniatinia.16@gmail.com \\ 2) Universitas Pelita Harapan - Tangerang \\ E-mail: yesaya6@gmail.com
}

\begin{abstract}
Baptism is one of the sacraments recognized by the church and is believed to be a seal for believers, and a sign of Christ's ownership. However, if you look at the practice in the church, many questions will arise, both regarding the instruments used in baptizing and the subjects to be baptized (children or adults). This is due to a lack of understanding of baptism as well as differences in interpretation of the Bible and the confession of faith used in the church. This difference results in the emergence of conflicts between churches and the courage of certain sects, thus making statements that the other sects are wrong or right. Despite believing or using the same Bible and creed, each church has a different understanding and way of implementing baptism in the church. Therefore, the church needs to be sensitive to this. The Church of God needs to have the same unity or standard of truth, so that in carrying out church discipline, it remains in accordance with the truth of God's Word, the Bible. Seeing the gaps or facts that occur in the church of God, the purpose of writing this paper is to show the views of two faith confessions recognized by the Reformed church regarding child baptism and show how the practice of baptism should be practiced in the church community of God.
\end{abstract}

Keywords: Child baptism, Heidelberg Cathecism, Confession of Westminster, church

\begin{abstract}
Abstrak
Baptisan adalah salah satu sakramen yang diakui oleh gereja dan diyakini sebagai meterai bagi orang-orang percaya, dan tanda kepemilikan Kristus. Namun, jika Anda melihat praktik di gereja, banyak pertanyaan akan muncul, baik mengenai instrumen yang digunakan dalam pembaptisan dan subyek yang akan dibaptis (anak-anak atau orang dewasa). Ini karena kurangnya pemahaman tentang baptisan serta perbedaan dalam penafsiran Alkitab dan pengakuan iman yang digunakan di gereja. Perbedaan ini menghasilkan munculnya konflik antara gereja dan keberanian dari sekte tertentu, sehingga membuat pernyataan bahwa sekte lain salah atau benar. Meskipun percaya atau menggunakan Alkitab dan kredo yang sama, setiap gereja memiliki pemahaman dan cara yang berbeda dalam menerapkan baptisan di gereja. Karena itu, gereja perlu peka terhadap hal ini. Gereja Allah perlu memiliki kesatuan atau standar kebenaran yang sama, sehingga dalam menjalankan disiplin gereja, itu tetap sesuai dengan kebenaran Firman Allah, Alkitab.
\end{abstract}


Melihat celah atau fakta yang terjadi di gereja Allah, tujuan penulisan makalah ini adalah untuk menunjukkan pandangan dua pengakuan iman yang diakui oleh gereja Reformed mengenai baptisan anak dan menunjukkan bagaimana praktik baptisan harus dipraktikkan di komunitas gereja. Tuhan.

Kata Kunci: Baptisan anak, Katekismus Heidelberg, Pengakuan Westminster, gereja

\section{PENDAHULUAN}

Baptisan adalah salah satu dari dua sakramen yang diakui oleh gereja Reformed. Thomas Watson menjelaskan bahwa hanya ada dua sakramen di Perjanjian Baru, yaitu Sakramen Baptisan dan Perjamuan Kudus. Kedua sakramen ini cukup bagi orang Kristen, baptisan sebagai tanda jalan masuk kita kepada Kristus, sedangkan Perjamuan Kudus sebagai pertumbuhan dan ketekunan kita di dalam Dia (Thomas, n.d.). Witsius menganalisis baptisan sebagai tanda dan meterai perjanjian kasih karunia tidak mengesampingkan doktrin Pemilihan Ilahi dari perjanjian itu. Ia bergabung dalam tujuan pemilihan Allah melalui Yesus Kristus dengan perjanjian Injili dalam darah Kristus (Herman, 2006).

Sakramen Baptisan yang menjadi tanda atau meterai bagi orang Kristen untuk masuk dalam komunitas gereja (umat Allah) (Millard J. Erickson, 2013). Baptisan menjadi tanda kesatuan umatNya dengan Allah. Seseorang tidak akan bisa memiliki kesatuan dengan .

Allah tanpa penghapusan kesalahan, karena jika manusia masih berada di bawah hukum dosa, maka manusia sama sekali tidak memiliki hubungan dengan Allah (Williamson, 2017). Menjadi milik Kristus merupakan kesucian yang membuktikan satu-satunya penghiburan seseorang dalam hidup dan mati. Tetapi tidak pantas bagi kita untuk berspekulasi tentang pemilihan karena ini adalah rahasia Allah, gereja tidak membaptis orang berdasarkan pengetahuan tentang pemilihan Allah (Herman, 2006). Namun, Sakramen Baptisan ini sering kali menjadi kontroversi antara berbagai golongan. Bukan hanya memperdebatkan ritual atau cara membaptis, melainkan juga memperdebatkan mengenai objek yang akan dibaptis (anak atau orang dewasa) (Ferguson, 2009). Terdapat beberapa gereja yang mengakui bahwa cara yang benar dalam membaptis harus dilakukan dengan percik, tetapi ada juga gereja yang mengakui bahwa cara membaptis yang benar harus dilakukan dengan selam. Perdebatan yang terjadi dikarenakan adanya perbedaan penafsiran dalam setiap aliran gereja. Hal ini harus menjadi evaluasi setiap gereja, karena gereja menggunakan Alkitab serta pengakuan iman yang sama namun memiliki perbedaan dalam menafsirkan maupun pengimplementasiannya.

Seharusnya gereja memiliki suatu kesatuan atau standar kebenaran yang sama, yaitu Alkitab. Alkitab adalah standar kebenaran yang mutlak, jika gereja benarbenar setia dengan Alkitab, maka akan sangat sedikit atau bahkan tidak ada penyimpangan, perbedaan dalam menafsirkan makna yang terkandung didalamnya. Oleh karena perbedaan yang terjadi dalam gereja, Sakramen Baptisan ini menimbulkan pertanyaan-pertanyaan bahkan beberapa aliran tertentu dengan berani memproklamasikan bahwa aliran ini benar atau salah (Bavinck, 2011). Selain itu, perdebatan ini sering terjadi 
karena sebenarnya banyak anggota gereja yang tidak dengan serius memahami pengertian dan tujuan dari baptisan. Baptisan dijadikan sebagai suatu tradisi atau kebiasaan yang harus dilakukan dalam sebuah gereja. Oleh karena itu, orang Kristen perlu memahami akan makna dari baptisan, sehingga fokus atau hal mendasar yang dipikirkan bukanlah mengenai teknis, ritual dari baptisan yang dilakukan, melainkan arti dari baptisan yang diberikan (Williamson, 2017). Orang Kristen perlu melihat kembali Firman Tuhan agar dalam pelaksanaan baptisan tetap berada pada koridor yang Allah kehendaki. Sebab apabila orang Kristen benar-benar menjalankan perintah Allah yang dituliskan dalam Alkitab, serta tidak bergantung pada pengertian pribadi dalam menafsirkan Firman Tuhan tersebut, maka dalam penerapannya di komunitas gereja akan benar serta orang Kristen akan memiliki pengertian yang benar mengenai baptisan.

Melihat perdebatan yang terjadi di antara umat kristiani, tujuan dari penulisan ini adalah menunjukkan pandangan dari dua pengakuan iman Kristen yaitu Katekismus Heidelberg dan Pengakuan Iman Westminster yang diakui oleh gereja Reformed mengenai baptisan anak dan bagaimana seharusnya praktik pelaksanaannya dalam komunitas gereja Kristus.

\section{SEJARAH BAPTISAN ANAK}

Perjanjian Baru menuliskan sangat sedikit tentang ritual atau cara baptisan. Matius 3 menyatakan bahwa baptisan yang dilayankan pertama kali oleh Yohanes Pembaptis kepada orang-orang pada masa itu, termasuk kepada Yesus Kristus di sungai Yordan (Ferguson, 2009). Baptisan anak tidak secara langsung disampaikan dalam Perjanjian Baru. Perjanjian Baru tidak meneguhkan, sebaliknya juga tidak menolak adanya baptisan anak. Pernyataan mengenai baptisan anak memang tidak didemonstrasikan dalam Pernjanjian Baru, namun hal itu tidak melawan praktik yang dilakukan (Ferguson, 2009). Beberapa teks Alkitab yang sering dihubungkan atau dikaitkan dengan baptisan anak yaitu Markus 10:13-16; Kis. 16:15; 1 Kor 1:16. Akan tetapi, tidak satupun dari teks tersebut yang membahas secara langsung mengenai baptisan anak (Emanuel Martasudjita, 2003). Oleh karena itu, pembahasan mengenai baptisan anak menjadi suatu pertanyaan bagi orang Kristen. Sejak kapan praktik baptisan anak ini dilakukan? Atau siapa yang pertama kali melakukan praktik tersebut?

Pada tahun 253 SM dan 220 SM, praktik baptisan anak disebutkan oleh Origenes dan Tertulianus. Bahkan pada zaman itu, praktik baptisan anak ini bukanlah suatu yang asing lagi. Praktik tersebut dianggap sebagai suatu warisan dari para rasul (murid-murid Kristus). Baptisan anak telah tersebar mulai abad kelima. Baptisan anak memiliki kaitan dengan perdebatan yang terjadi antara gereja dengan Pelagianisme mengenai dosa asal. Pelagianisme memiliki pandangan bahwa kejatuhan Adam ke dalam dosa tidak diwariskan kepada keturunan-keturunan selanjutnya, kecuali jika manusia selanjutnya mengikuti teladan Adam yang buruk atau jahat (F. D. Wellem, 2003).

Agustinus memberikan penjelasan mengenai perdebatan yang terjadi tersebut dengan membahas baptisan anak. Maksudnya ialah baptisan anak mengidentifikasikan adanya suatu pengampunan dosa. Agustinus menjelaskan bahwa dalam diri manusia telah ada dosa asal (warisan dari Adam) dan dosa pribadi yang mungkin belum dilakukan oleh seorang anak. Ajaran Agustinus ini diterima dan diteguhkan dalam berbagai konsili Karthago (DS 418), Lateran VI (DS 1215), serta konsili Trente (DS 1514 dan 1625-1627) (Emanuel Martasudjita, 2003). Sedangkan pandangan Pelagius dinyatakan bidat dan 
dikutik pada konsili 416-418 di Kartago (Kaligis \& Manogu, 2020).

Dalam tulisan Petrus Lombardus, pada Abad Pertengahan, baptisan termasuk dalam salah satu dari tujuh sakramen yang diakui gereja. Akan tetapi, pada awal tahun 1520-an para tokoh Reformed menguragi jumlah sakramen, serta menetapkan dua sakramen yaitu Perjamuan Kudus dan Baptisan. Zwingli juga memberikan argumennya mengenai baptisan anak. Awalnya Zwingli memiliki keragu-raguan karena ia kesulitan untuk menjelaskan pengertian dosa asal yang dijelaskan oleh Agustinus pada abad kelima. Namun, Zwingli memberikan suatu pengertian yang berbeda dengan melihat pada Perjanjian Lama. Di mana anak laki-laki harus disunat beberapa hari setelah ia dilahirkan. Hal ini menunjukkan adanya tanda bahwa anak yang disunat tersebut menjadi anggota dari umat Israel atau dengan kata lain, sunat membawa manusia ke dalam persekutuan perjanjian Allah dengan umat-Nya. Melalui pemahaman ini, Zwingli melihat bahwa baptisan adalah suatu kesaksian akan kesetiaan kepada Allah secara umum (McGrath, 2006).

Senada dengan Zwingli, Calvin dengan yakin menyetujui adanya baptisan anak. Calvin mengatakan bahwa baptisan anak membawa anak masuk dalam komunitas gereja. Calvin menyatakan bahwa jika anak-anak Kristen tidak dibaptis, maka mereka tidak memiliki hubungan dengan anak-anak Yahudi (umat Allah). Maksud Calvin pada bagian ini adalah baptisan bagaikan meterai yang memeteraikan setiap anak orang Kristen dengan janji Allah, namun jika mereka tidak dibaptis, maka mereka bukanlah umat Allah atau tidak masuk dalam perjanjian Allah. Oleh karena itu, Calvin menyatakan bahwa anak-anak Kristen seharusnya dibaptis dan jangan menolak manfaat yang diberikan. Manfaat yang didapatkan, antara lain; anak akan dimasukkan dalam tubuh gereja, setelah anak menjadi dewasa, maka baptisan menjadi dorongan yang besar bagi mereka untuk benar-benar menyembah Allah, yang telah mengangkat mereka sebagai anak-anak-Nya melalui tanda pengangkatan resmi yang dilayankan oleh pejabat gereja di hadapan jemaat Tuhan. Pemahaman yang diberikan oleh tokoh Reformed pada zaman itu menjadi pegangan atau dasar dari praktik-praktik baptisan anak di gereja-gereja pada zaman ini.

Meskipun tidak semua aliran gereja menerapkannya karena memiliki dasar yang berbeda namun perlu dipahami bahwa baptisan anak memberikan perbedaan antara anak orang percaya dengan anak-anak yang lainnya (Calvin, 2008).

\section{BAPTISAN ANAK DALAM KATEKISMUS HEIDELBERG}

Katekismus Heidelberg ini dikelompokkan dalam the continental confessions of the Reformed tradition bersama dengan French, 1559; Belgic, 1561; Heidelberg Catechism, 1563. Pengakuan ini memberikan penekanan dalam banyak hal yang sama, khususnya dalam hal baptisan. Sakramen Baptisan dipahami sebagai "janji" dan "semangat" yang ditambahkan pada firman Allah sebagai tanda yang melampaui pekerjaan Allah dan melalui mana pekerjaan-pekerjaan Allah. Ide-ide perjanjian dan pemilihan adalah penting, seperti pertanyaan eksistensial tentang iman dan manfaat yang diperoleh orang yang dibaptis (F. D. Wellem, 2003).

The Catechism defines baptism to be an external washing with water instituted by Christ, to which this promise is added, that when we are baptized, we are as certainly washed by his blood and Spirit from all the pollution of our souls, that is from all our sins, as we are washed externally with water, by which the filthiness of the 
body is commonly washed away." (G. W. Williard, 2004)

Baptisan memberikan gambaran bahwa pembersihan atau penyucian yang dilakukan dengan air memberikan dampak bagi kehidupan manusia berdosa. Pembasuhan dengan air menggambarkan bahwa manusia dibasuh oleh darah dan Roh-Nya dari segala kecemaran di dalam jiwa. Hal ini sama artinya jika manusia dibasuh dengan air.Pertanyaan yang diajukan dalam Katekismus Heidelberg mengenai Baptisan bayi atau anak memberikan penekanan yang cukup jelas untuk dimengerti oleh jemaat Tuhan. Katekismus Heidelberg tidak hanya memberikan pertanyaan yang spesifik mengenai Baptisan anak atau bayi, melainkan juga memberikan jawaban yang sangat jelas, tegas mengenai Baptisan, serta memberikan tujuan dilakukannya Baptisan anak.

Yes. For since they, as well as their parents, belong to the covenant and people of God, and both redemption from sin and the Holy Spirit, who works faith, are through the blood of Christ promised to them no less than to their parents: they are also by Baptism, as a sign of the covenant, to be engrafted into the Christian Church, and distinguished from the children of unbelievers, as was done in the Old Testament by Circumcision, in place of which in the New Testament Baptism is appointed." (G. W. Williard, 2004)

Baptisan harus dilayankan kepada anak atau bayi, meskipun mereka belum mengenal atau memiliki iman kepada Kristus. Iman orang tua merekalah yang membawa mereka masuk dalam komunitas gereja. Baptisan yang diberikan juga menuntut orang tua untuk membimbing anak untuk bertumbuh dalam pengenalan akan Kristus. Pernyataan ini sejalan dengan penjelasan Zwingli yang mengatakan bahwa baptisan sama dengan sunat yang di Perjanjian Lama. Katekismus Heidelberg juga memberikan penjelasan mengenai hal ini.

Under the Old Testament infants were circumcised as well as adults. Baptism occupies the place of circumcision in the New Testament, and has the same use that circumcision had in the Old Testament. Therefore infants are to be baptized as well Lord's Day 27659 as adults. The first proposition needs no proof. The second is proven by what the apostle Paul says: "You are circumcised with the circumcision made without hands, in putting off the body of the sins of the flesh, by the circumcision of Christ: buried with him in baptism, wherein you are also risen with him." (Col. 2:11, 12) Baptism, therefore, is our circumcision, or the sacrament by which the same things are confirmed unto us, and to as many under the New Testament as under the Old by circumcision." (G. W. Williard, 2004)

Senada dengan pernyataan di atas, Calvin dalam bukunya yang berjudul Institutio juga menyatakan bahwa baptisan yang ada dalam Perjanjian Baru memiliki persamaan dengan sunat di Perjanjian Lama. Pertama, janji. Janji yang dimaksudkan Calvin disini ialah "anugerah bahwa Allah menjadi Bapa kita, pengampunan dosa, dan kehidupan yang kekal." Selain itu, Calvin juga menegaskan bahwa dalam Alkitab, diberikan pengetahuan yang pasti bahwa anak-anak orang Yahudi disebut sebagai "anak-anak kudus" sehingga mereka dinyatakan 
sebagai ahli waris perjanjian dan dibedakan dari anak-anak orang fasik. Sama halnya dengan anak-anak orang percaya juga dikatakan kudus dan menjadi alhi waris, meskipun hanya salah satu dari orang tuanya yang adalah orang percaya. Oleh sebab itu, baptisan harus dilayankan kepada anak-anak (Calvin, 2008).

Struktur katekismus dibagi menjadi tiga bagian utama, pertama berkaitan dengan dosa dan kesengsaraan manusia, kedua tentang penebusan yang disediakan melalui karya Yesus Kristus, dan ketiga tentang masalah kehidupan orang Kristen yang penuh syukur. Sakramen dibahas dalam bagian kedua yang berhubungan dengan karya penebusan Kristus dan komunikasi tentang manfaat keselamatan melalui mediasi gereja. Melalui sakramen kita dijadikan sebagai bagian dari Kristus atau dengan kata lain anak-anak yang dibaptis telah bergabung dalam komunitas gereja. Katekismus Heidelberg menegaskan bahwa Roh Kudus bekerja dalam hati kita dengan "pemberitaan Injil" dan mengukuhkannya dengan menggunakan sakramen-sakramen suci. Digunakan kata kerja yang berbeda untuk menggambarkan pekerjaan Roh Kudus melalui instrumen khotbah dan sakramen. Khotbah "menghasilkan" iman, sakramensakramen "mengkonfirmasi" iman. Sakramen bukan untuk melengkapi apa yang dijanjikan firman, tetapi sakramen membuktikan dan menegaskan kebenaran firman (Collins, 2012).

Katekismus Heidelberg memiliki suatu aksen yang sama dengan Pengakuan Iman Belgic bahwa sakramen memungkinkan orang percaya untuk memahami janji injil yang lebih jelas, sehingga Allah "dapat memberikan meterai pada janji itu”. Dalam hal ini yang dimaksudkan dengan janji Allah adalah pengampunan dosa-dosa kita dan memberikan kita hidup yang kekal. Semua ini hanya didapatkan oleh karena anugerah dari kemurahan Allah. Janji baptisan juga datang sebagai janji pribadi, sehingga dengan tanda lahiriah datang juga janji bahwa kenajisan, semua dosa telah dibasuh dengan darah-Nya dan Roh-Nya. Dibasuh dengan Roh Kristus berarti Roh Kudus telah memperbaharui dan menetapkan orang-orang yang dibaptis untuk menjadi anggota komunitas Kristus. Orang-orang yang dibaptis seharusnya hidup kudus dan menjalani hidup dengan suci dan tidak bercela serta semakin menghindarkan diri untuk berbuat dosa. Baptisan bayi dalam Katekismus Heidelberg menegaskan bahwa anak-anak dengan orang dewasa merupakan bagian dari umat perjanjian Allah, maka anakanak sama dengan orang dewasa yang juga dijanjikan pengampunan dosa melalui darah Kristus dan Roh Kudus yang menghasilkan iman (Mark, 2004). Katekismus Heidelberg dalam pembahasannya mengenai Baptisan Anak menyatakan bahwa semua anak-anak Kristen harus dibaptis. Hal ini diungkapkan karena anak-anak juga adalah bagian dari perjanjian yang telah Allah janjikan kepada umat-Nya. Selain itu, dengan dibaptisnya anak-anak orang percaya, maka mereka dimasukkan dalam komunitas gereja Kristen serta memberikan tanda pembeda antara anakanak orang percaya dengan anak-anak yang tidak percaya. Baptisan Anak adalah harus dilakukan oleh keluarga Kristen karena Baptisan Anak adalah bagian dari perjanjian yang Allah berikan sama seperti yang Allah perintahkan pada masa Perjanjian Lama yaitu sunat yang dalam Perjanjian Baru kita kenal sebagai Baptisan Anak.

Sakramen berfungsi untuk peristiwa salib menjadi lebih efektif dan melalui sakramen gereja mengambil bagian dalam pengorbanan Kristus. Dalam baptisan digambarkan "peringatan" sebagai aktualisasi pengorbanan Kristus, Gereja, dan di depan Bapa. Thurian berpendapat bahwa rekonsiliasi yang objektif telah di penuhi sepenuhnya oleh Kristus di kayu salib, tetapi Gereja sebagai tubuh Kristus 
memiliki tugas untuk menjalankan sakramen yang telah diperintahkan. Membawa anak-anak ke Gereja merupakan kewajiban orangtua, Alkitab mencatat bahwa anak-anak harus dibiarkan datang kepada-Nya (Markus 10:14). Oleh karena orang tua bertugas untuk membawa anak-anaknya untuk dibaptis, maka orang tua juga bertanggung jawab untuk mengajarkan kebenaran Allah kepada anak tersebut. Hal ini bertujuan agar anak bisa memiliki pengenalan akan Tuhan yang benar.

\section{BAPTISAN ANAK DALAM PENGAKUAN IMAN WESTMINSTER}

Baptisan merupakan salah satu jenis dari sakramen. Baptisan adalah "suatu sakramen Perjanjian Baru yang ditetapkan oleh Yesus Kristus dan suatu tanda serta meterai dari kovenan anugerah, pencangkokan dirinya ke dalam Kristus, kelahiran baru, pengampunan dosa, penyerahan hidupnya kepada Allah melalui Yesus Kristus, untuk berjalan di dalam hidup yang baru" (Williamson, 2017). Baptisan dilakukan di dalam sebuah gereja. Baptisan dilakukan oleh seorang pelayan Injil yang ditetapkan di dalam gereja tersebut. Setiap orang Kristen wajib dibaptis, baptisan di perintahkan langsung oleh Kristus. Baptisan tercatat dalam injil Matius 28:19, semua bangsa harus dibaptis di dalam nama Bapa, Anak, dan Roh Kudus.

Baptisan tidak hanya diberikan kepada orang dewasa, tetapi kepada semua anak-anak orang percaya. Konsep utama Baptisan adalah sebuah kesatuan, yaitu kesatuan dengan Allah melalui Kristus. Allah mampu menciptakan kesatuan dalam diri anak-anak sehingga tidak ada alasan bagi anak-anak untuk tidak dibaptis. Baptisan hanya dilakukan satu kali saja yaitu dalam nama Bapa, Anak dan Roh Kudus karena sekali saja sudah mencerminkan kecukupan anugerah Allah. Unsur yang digunakan dalam baptisan adalah air. Kristus telah berfirman bahwa baptisan harus dilakukan sampai akhir zaman (Matius 28:20). Baptisan tidak menyelamatkan, karena keselamatan hanya diperoleh berdasarkan kasih karunia melalui iman kepada Yesus Kristus, baptisan hanya sebagai meterai atau tanda. Tanda (sign) berasal dari bahasa latin, yaitu signum, merupakan suatu yang menyatakan sesuatu hal atau bukti, pengenalan, lambang yang menunjukkan sesuatu yang lain atau berbeda (Emanuel Martasudjita, 2003).

Pengakuan Iman Westminster juga memberikan penjelasan mengenai cara baptisan. Baptisan dilakukan dengan mencurahkan atau memercikkan air ke atas orang yang dibaptis, sehingga tidak perlu menyelamkan seseorang ke dalam air. Baptisan air merupakan suatu upacara terbuka bagi awal pemasukan ke dalam Kristus (Stott, 1999). Upacara ini merupakan tanda penyucian dosa (kis 22:16) dan pemberian Roh Kudus. Secara umum Baptisan adalah matrikulasi atau masuknya anak-anak ke dalam kawanan domba Kristus.

Secara khusus Baptisan merupakan sakramen yang dilakukan dengan cara memercikkan air di dalam nama Bapa, Anak, dan Roh Kudus, menandakan dan memeteraikan pencangkokan orang-orang yang dibaptis ke dalam Kristus serta mengambil bagian dari manfaat perjanjian kasih karunia dan pertunangan kita untuk menjadi milik Kristus.

Orang tua wajib membawa anakanaknya untuk di baptis dalam gereja, makna dari orang tua membawa anaknya untuk dibaptis yaitu, pertama orang tua membuat pengakuan di muka umum bahwa jiwa anaknya telah tercemar dosa (dosa asal) sehingga dosa anak tersebut harus dibasuh oleh darah Kristus yang ditandai dengan percikan air. Kedua adalah orang tua dengan serius mengabdikan anaknya kepada Tuhan dan menjadi bagian keluarga Allah (Thomas, n.d.).Baptisan tidak hanya berbicara 
tentang penerimaan yang sungguhsungguh ke dalam sebuah gereja yang kelihatan, tetapi baptisan memberi tanda dan meterai perjanjian kasih karunia, regenerasi, pengampunan dosa, pembentukannya di dalam Kristus dan hidup yang baru melalui Yesus Kristus. Baptisan tidak terkait dengan momen waktu dimana seseorang dibaptis, anugerah yang dijanjikan akan benarbenar diperlihatkan menurut nasihat kehendak Allah sendiri dalam petunjuknya dan waktunya karena itu adalah milik Allah.

Westminster menggunakan definisi teknis dari "efficacy" yaitu pemberian dan partisipasi yang langgeng dalam Kristus. Dalam pengertian ini baptisan hanya "efficacious" hanya untuk orang-orang pilihan walaupun orang itu datang lebih lambat dari pada waktu baptisan. Baptisan bagi orang yang tidak terpilih tidak akan "efficacious" berdasarkan pengertian ini. Westminster menyangkal hal ini karena biasanya orang-orang mendengar dari penganut Presbiterian evangelis tidak akan ada hal yang terjadi ketika orang yang tidak dipilih dibaptis. Ini bukan hal yang dikatakan oleh Westmisnter. Bahasa dalam Westminster mengklarifikasi bahwa persatuan ini berbeda dengan orang-orang yang dipilih dan tidak dipilih, tetapi dengan jelas tidak memberikan kriteria untuk membedakan keduanya (Collins, 2012).

\section{BAPTISAN ANAK DALAM PENERAPANNYA DI GEREJA}

Gereja masa kini harus sadar dan benar-benar mengerti mengenai Baptisan Anak. Hal ini penting agar dalam praktiknya dalam gereja lebih baik dan tetap setia pada firman Tuhan. Ketika menggunakan pengakuan iman yang diakui dan digunakan oleh gereja mulamula sebagai pengakuan iman dalam gereja khususnya mengenai baptian anak, gereja Kristen perlu peka terhadap penafsiran yang menyimpang yang tidak sesuai dengan kebenaran Alkitab. Hal ini dilakukan agar praktik-praktik disiplin rohani yang diterapkan dalam gereja tidak bertentangan dengan kebenaran Allah.

Calvin dengan tegas menyatakan bahwa konsekuensi dari ikatan baptisan adalah pelayanan ini harus dilaksanakan atau terjadi dalam kebaktian jemaat oleh pendeta selaku pejabat yang telah ditentukan oleh gereja. Pandangan ini senada dengan pandangan Zwingli yang menyatakan bahwa baptisan adalah tindakan pengakuan (de Jonge, 2008). Selain itu, Calvin juga menegaskan bahwa baptisan tidak dilakukan atau dilayankan oleh wanita dan orang-orang yang bukan pejabat gereja atau para rasul (Calvin, 2008).

Katekismus Hidelberg memang tidak menjelaskan bagaimana cara atau praktik Baptisan Anak dalam gereja, karena hanya menjelaskan bahwa anakanak orang Kristen harus dibaptis dengan menggunakan air.

Akan tetapi, Katekismus Westminster memberikan penjelasan mengenai cara pelaksaan baptisan yang seharusnya dalam gereja. Pertama, Allah tidak memerintahkan umat-Nya baptisan selam. Kedua, baptisan tidak perlu menggunakan cara selam. Ketiga, baptisan Roh Kudus yang terjadi dengan pencurahan (Kis. 1:5, 8; 2:17). Roh Kudus dicurah kepada murid-murid Yesus. Murid-murid tidak diselam ke dalam Roh Kudus. Hal ini memberikan pengertian bahwa baptisan yang agung diberikan dengan pencurahan, maka baptisan dengan air juga akan dicurahkan (Williamson, 2009). Selain berbicara mengenai siapa dan bagaimana cara melakukan baptisan anak, Katekismus Westminster juga memberikan penjelasan dengan melihat Perjanjan Lama dan Perjanjian Baru. Perjanjian Lama yang menjadi tanda atau meterai adalah sunat (Kej. 17:7). Sunat dilaksanakan satu kali kepada orang percaya dan keturunannya. Sunat dilakukan sebagai lambang 
pembersihan dari dosa yang ditandai dengan pencurahan darah. Perjanjian Baru dilakukan dalam bentuk baptisan (Kis 2:39; Gal. 3:29). Baptisan dilaksanakan satu kali pada orang percaya dan keturunannya. Baptisan dilakukan sebagai lambang pembersihan dari dosa tetapi tanpa adanya pencurahan darah (Williamson, 2009).

Sunat dan baptisan hanya dilakukan satu kali bagi orang percaya serta keturunannya. Gereja harus menyadari dan memberikan perhatian akan hal ini, karena beberapa gereja Kristen mengharuskan jemaat yang baru bergabung melakukan baptisan kembali meskipun di gereja yang duhulu ia telah dibaptis dalam nama Bapa dan Anak dan Roh Kudus. Praktik seperti ini perlu melihat lagi kepada kebenaran Firman Tuhan, agar dalam pelaksanaan baptisan benar-benar Allah yang dimuliakan dan bukan keinginan gereja. Baptisan merupakan hal yang dirancang untuk dilakukan di dalam Gereja sampai akhir zaman, terkadang Gereja dibingungkan dengan praktik dalam baptisan sehingga memunculkan berbagai pendapat yang berbeda dalam membaptis. Dalam commentary Westminster dijelaskan bahwa membaptis dilakukan dengan air, tetapi bagaimana cara melakukannya tidak menjadi sebuah permasalahan. Gereja sering kali kontroversi mengenai masalah ritual yang dilakukan di dalam Gereja, tetapi sebenarnya ritual bukan menjadi sebuah permasalahan yang utama, yang terpenting adalah instrumen yang digunakan, yaitu air atas nama Trinitas (Hodge, 2015).

\section{PEMBAHASAN}

Yesus memberikan perintah kapada murid-murid-Nya yang tertulis dalam kitab Matius 28:19-20 "Karena itu pergilah, jadikanlah semua bangsa murid$\mathrm{Ku}$ dan baptislah mereka dalam nama Bapa dan Anak dan Roh Kudus, dan ajarlah mereka melakukan segala sesuatu yang telah Kuperintahkan kepadamu. Dan ketahuilah, Aku menyertai kamu senantiasa sampai kepada akhir zaman." Yang penting dalam melakukan baptisan adalah subjek atau nama yang dipakai dalam baptisan, objek atau siapa yang menerima baptisan (orang dewasa atau bayi) (Berkhof, 2009). Baptisan Anak dalam Katekismus Heidelberg terlihat jelas dinyatakan bahwa anak-anak kecil harus dibaptis karena mereka sama dengan orang dewasa yaitu termasuk dalam perjanjian Allah.

Baptisan Anak dalam Katekismus Heidelberg hanyalah tanda pembeda antara anak orang yang percaya dengan anak dari orang tidak percaya. Hal yang berbeda dapat ditemukan dalam Pengakuan Iman Westminster yaitu tidak dinyatakan secara spesifik mengenai Baptisan Anak yang harus dibaptis. Pengakuan Iman Westminster hanya mengungkapkan bahwa janji yang Roh Kudus limpahkan itu adalah untuk anakanak dan orang dewasa. Selain itu, dalam Pengakuan Iman Westminster dinyatakan bahwa tujuan dari baptisan adalah tanda kelahiran kembali.

Hal ini menjadi pertanyaan yang cukup besar apabila baptisan yang ditujukan itu diberikan kepada anak-anak yang sama sekali belum memiliki pengenalan akan Tuhan. Bahkan jika anak itu dibaptis saat bayi (beberapa setelah ia lahir), anak itu sama sekali tidak memiliki pengetahuan apapun, untuk berbicara pun, anak itu belum dapat melakukannya. Bagaimana mungkin ada kelahiran kembali? tujuan baptisan dan siapa yang harus dibaptislah yang memberikan perbedaan antara Katekismus Heidelberg dengan Pengakuan Iman Westminster. Meskipun kedua pengakuan ini sepakat bahwa baptisan adalah tanda atau meterai akan janji Allah, tetapi ada beberapa bagian yang membuat adanya perbedaan. Katekismus Heidelberg memberikan penjelasan serta penegasan yang signifikan serta spesifik mengenai baptisan anak 
orang-orang percaya. Hal inilah yang menjadi pedoman bagi umat Kristen. Namun, bukan berarti bahwa Pengakuan Iman Westmintser memiliki kesalahan atau lebih buruk daripada Katekismus Heidelberg, melainkan beberapa prinsip Baptisan Anak lebih jelas dinyatakan dalam Heidelberg.

Pembahasan mengenai Baptisan Anak dalam Katekismus Heidelberg dan Pengakuan Iman Westminster dituliskan untuk melawan kaum Anabaptis yang menentang adanya baptisan bayi. Pandangan kaum Anabaptis adalah bayi belum memiliki pengalaman mengenai pertobatan yang dilambangkan dalam baptisan (Williamson, 2009). Akan tetapi, Heidelberg dan Westminster memberikan jawaban bahwa baptisan adalah bagian dari perjanjian (kovenan) Allah kepada umat-Nya. Baptisan Anak memberikan pengertian bahwa anak itu masuk dalam perjanjian Allah dengan umat-Nya. Oleh karena itu, semua anak orang-orang Kristen haruslah menerima baptisan.

Katekismus Heidelberg tidak memberikan perbedaan antara bayi atau anak dengan orang dewasa mengenai baptisan. Namun yang menjadi perhatian dalam Katekismus Heidelberg adalah peran orang tua yang sangat besar untuk memberikan pengajaran kepada anak mengenai firman Tuhan. Saat dibaptis, anak memang belum memiliki pengetahuan tentang Tuhan, dan pandangan inilah yang ditentang oleh kaum Anabaptis. Akan tetapi, Katekismus Heidelberg memberikan penjelasan yang sangat baik kepada jemaat Tuhan mengenai hal ini.

Therefore, they are not fit subjects for baptism. Ans. The major proposition is true of adults, who are capable of being taught, from which class of persons the first members of the church were gathered. These Christ command first to be taught, and then to be baptized, so as to be distinguished from the world. But it is false if applied to infants who are born in the church, or who become connected with it when their parents believe and make a profession of their faith; because, Christ does not speak of infants, but of adults, who are capable of being taught, and who ought not to be received into the church unless they are first taught. Infants are included in the covenant, because God says, "I will be a God unto thee and thy seed," even before they were capable of being instructed. Therefore, they are also to be baptized. (Williard, 2010)

Pengakuan Iman Westminster menyatakan bahwa baptisan membuat seseorang atau anak yang dibaptis menjadi anggota komunitas gereja yang kelihatan, menerima anugerah dari Allah serta menerima berkat dari perjanjian Allah. Berkat-berkat yang diterima adalah kesatuan dalam Kristus, pengampunan dosa melalui darah Yesus serta kelahiran kembali yang dikerjakan oleh Roh Kudus (Hodge, 2015). Pengakuan Iman Westminster juga memberikan penjelasan mengenai tugas orang tua yang harus memberikan pengajaran kepada anaknya mengenai Firman Tuhan. Anak belum memiliki pengetahuan dan mengerti kebenaran Allah, oleh sebab itu, mereka memerlukan bimbingan dari orang tua atau mereka yang dewasa.

Calvin menyatakan bahwa baptisan adalah jaminan kita yaitu konfirmasi janji yang ada di injil Tuhan. Baptisan dalam Westminster dilayankan tidak hanya bagi orang dewasa yang beriman tetapi juga bagi anak-anak mereka. Westminster memberikan catatan khusus tentang Baptisan Bayi. Pengakuan Iman 
Westminster mengatakan bahwa tidak ada bukti tertulis mengenai Baptisan Bayi, tetapi berdasar pada pemahaman yang menyatakan bahwa Allah akan berurusan kepada umat-Nya melalui perjanjian. Oleh sebab itu, baptisan juga dilayankan bagi bayi (Spear, 2006).

Kedua pengakuan iman yang diterima oleh aliran Reformed menerima adanya Baptisan Anak. Kedua pengakuan ini memberikan pandangan yang pada hakikatnya adalah sama. Memberikan penjelasan mengenai tujuan dan bagaimana penerapannya dalam komunitas gereja. Menggunakan nama Allah Tritunggal dalam melakukan baptisan serta menggunakan air yang dijadikan sebagai tanda pembasuhan dosa manusia. Namun, yang menjadi perbedaan dari pengakuan iman ini adalah pembahasan mengenai haruskah bayi atau anak dibaptis? Dalam Katekismus Heidelberg benar-benar dijelaskan dan tegaskan bahwa bayi atau anak harus dibaptis untuk memberikan perbedaan antara anak-anak orang percaya dengan mereka yang bukan percaya. Sedangkan dalam Pengakuan Iman Westminster, pembahasan mengenai Baptisan Anak tidak begitu spesifik dibahas, bahkan dikatakan bahwa Baptisan Anak tidak didasarkan oleh bukti tertulis dan hanya berdasarkan pada pemahaman bahwa Allah akan mengikat mereka yang dibaptis melalui perjanjian yang telah Ia buat.

Hal ini memberikan gambaran bahwa Pengakuan Iman Westminster mendukung adanya baptisan yang tidak hanya dilayankan kepada orang dewasa yang beriman tetapi juga kepada anakanak mereka. Pernyataan tersebut menyatakan bahwa anak atau bayi bisa saja dibaptis apabila orang tua membawanya ke gereja dan menerima pelayanan baptisan, tetapi juga saat dewasa nanti ia akan menerima pelayanan Baptisan Kudus. Berbeda dengan Katekismus Heidelberg, kata harus yang digunakan mengandung makna yang besar dan menjadi suatu perintah bagi orang percaya. Pernyataan tersebut memberikan gambaran bahwa anak sangat perlu menerima pelayanan baptisan. Katekismus Heidelberg tidak hanya memberikan suatu penegasan atau suatu keharusan bagi atas baptisan anak, melainkan juga memberikan penjelasan mengenai alasan bayi harus dibaptis. Heidelberg menjelaskan bahwa apabila anak itu dibaptis, maka mereka akan masuk dalam perjanjian Allah dengan umat-Nya atau dengan kata lain anak itu terhitung sebagai anggota jemaat Allah. Selain itu, Heidelberg juga menegaskan bahwa anak itu akan dipisahkan dari anakanak yang bukan orang percaya. Hal ini yang menjadi jaminan akan janji Allah bagi umat-Nya.

Baptisan tidak menyelamatkan, kedua pengakuan iman ini setuju akan hal tersebut. Namun, dengan adanya baptisan, maka orang Kristen masuk dalam komunitas atau miliki sebuah komunitas gereja serta menerima berkat-berkat perjanjian Allah (Ferguson, 2009). Orangorang yang menerima baptisan kepadanya telah dimeteraikan sebagai umat yang masuk dalam persekutuan dengan Kristus.

\section{KESIMPULAN}

Pandangan kedua pengakuan iman yang diakui oleh gereja Reformed, yaitu Katekismus Heidelberg dan Pengakuan Iman Westminster memiliki beberapa persamaan serta perbedaan. Kedua pengakuan iman ini menerima Baptisan Anak diterapkan dalam gereja. Selain itu, pemahaman yang memiliki oleh kedua pengakuan ini ialah bahwa setiap orang dibaptis telah dimeteraikan dan masuk dalam komunitas gereja Allah (perjanjian Allah). Akan tetapi, terdapat perbedaan diantara keduanya yang tidak begitu besar sampai mengubah makna baptisan, yaitu kesatuan dengan Kristus. Perbedaan dari kedua pengakuan terlihat dari penekanan dan tujuan dari Baptisan. Pengakuan Heidelberg menyatakan bahwa anak-anak 
harus dibaptis, pernyataan ini merupakan suatu kewajiban yang harus dilakukan oleh orang tua yang percaya kepada Kristus. Menurut Katekismus Heidelberg, membaptis anak adalah wajib dan bukan pilihan. Sedangkan Pengakuan Iman Westminster tidak secara spesifik menyatakan bahwa anak-anak itu harus dibaptis, tetapi Pengakuan Iman Westmisnter hanya menyatakan bahwa baptisan boleh dilayankan kepada anakanak atau orang dewasa. Pengakuan ini tidak memberikan suatu penekanan seperti yang ada di Katekismus Heidelberg. Akan tetapi, Pengakuan Iman Westminster memberikan pengetahuan bagaimana seharusnya baptisan diterapkan dalam praktik gereja. Tidak mengalihkan fokus pada ritual melainkan berfokus pada perintah Yesus dalam melakukan baptisan yaitu, membaptis anak di dalam nama Bapa, dan Anak, dan Roh Kudus. Hal inilah yang menjadi perbedaan antara dua pengakuan gereja ini. Penjelasan mengenai ritual yang kurang dijelaskan dalam Katekismus Heidelberg namun dijelaskan dengan detail dalam Pengakuan Iman Westminster.

Penulis melihat bahwa kedua pengakuan tersebut memiliki pandangan yang tidak jauh berbeda. Akan tetapi, Katekismus Heidelberg lebih memberikan penekanan dan pemahaman yang sangat jelas mengenai Baptisan Anak. Penekanan ini memberikan pengertian yang jelas bagi kalangan gereja Allah, karena tujuan dari Katekismus Heidelberg adalah pengajaran bagi anak muda serta penuntun bagi para pendeta atau guru, sehingga dalam penerapan Baptisan Anak ini mudah untuk diterapkan dalam praktik gerejawi.

\section{DAFTAR PUSTAKA}

[1]. Bavinck, H. (2011). Reformed Dogmatics. Grand Rapids: Baker Academic.
[2]. Berkhof, L. (2009). A Summary of Christian Doctrine. USA: Wm. B. Eerdmans.

[3]. Calvin, Y. (2008). Institutio [Christianae religionis]: Pengajaran agama Kristen (6th ed.; N. Winarsih, J. . Aritonang, Arifin, \& T. Van den edn, Trans.).

[4]. Retrieved from

https://books.google.co.id/books?id $=$ IyyoWYGxdYAC\&printsec $=$ front cover\&hl=id\&source=gbs_ge_sum mary_r\&cad $=0 \# \mathrm{v}=$ onepage $\& \mathrm{q} \& \mathrm{f}=\mathrm{f}$ alse

[5]. Collins, J. (2012). What does baptism do for anyone? Part II: additional studies. Presbyterion, 126.

[6]. de Jonge, C. (2008). Apa itu Calvinisme? (R. U. NapitupuluSimarangkir, Ed.). Retrieved from books.google.co.id/books?id=F9KB AZ7hJDAC\&pg=PA195\&dq=sakra men + menurut+calvin\&hl $=\mathrm{id} \& \mathrm{sa}=\mathrm{X}$ \&ved $=0$ ahUKEwin0vWiyM3nAhX hyzgGHZ9gBgAQ6AEIKTAA\#v= onepage $\& \mathrm{q}=$ sakramen menurut calvin $\& \mathrm{f}=$ false

[7]. Emanuel Martasudjita. (2003). Sakramen-Sakramen Gereja: Tinjuan Teol, Liturgis, Pastoral. Yogyakarta: Kanisius.

[8]. F. D. Wellem. (2003). Riwayat Hidup Singkat Tokoh-tokoh dalam sejarah gereja. Jakarta: Gunung Mulia.

[9]. Ferguson, E. (2009). Baptism in the Early Church: History, Theology, and Liturgy in the First Five Centuries. Grand Rapids: Wm. B. Eerdmans,.

[10]. G. W. Williard, A. M. (2004). The Commentary of DR. Zacharias Ursinus on the Heidelberg Catechsim (Eric D. Bristley, Ed.). 
UNITED STATES: The Synod of the Reformed Church in the U.S.

[11]. Herman, W. (2006). On the efficacy and utility of baptism in the case of elect infants whose parents are under the covenant. Mid-America Journal of Theology, 1-71.

[12]. Hodge, A. A. A. (2015). The Westminster Confession: A Commentary. Retrieved from https://books.google.co.id/books?id= ueC7CgAAQB

[13]. Kaligis, F. R., \& Manogu, R. (2020). Analisis Teologis Konsep Pembenaran Berdasarkan Pengakuan Iman Westminster dan Katekismus Heidelberg. Diligentia: Journal of Theology and Christian Education, 2(1), 103-104. https://doi.org/http://dx.doi.org/10.19 166/dil.v2i1.2285

Heyns' Doctrine of the Covenant and the Apostasy of Covenant

[14]. Mark, B. (2004). The promise of the covenant and the enigma and unbelief: Reflections on Covenant Promise, with a Selection from Samuel Volbeda's "Catechetics," Offering a Critique of William

Youth. Mid-America Journal of Theology, 1-40.

[15]. McGrath, A. E. (2006). Sejarah Pemikiran Reformasi. Jakarta: BPK Gunung Mulia.

[16]. Millard J. Erickson. (2013). Christian Theology. Grand Rapids: Baker Academic.

[17]. Spear, R. W. (2006). Faith of Our Fathers: A Commentary on the Westminster Confession of Faith. Pittsburgh: Crown \&amp; Covenant Publ.

[18]. Stott, J. (1999). Baptisan dan Kepenuhan (Ketiga; H. Hadiwijono,
Trans.). Jakarta: Yayasan Komunikasi Bina Kasih.

[19]. Thomas, W. (n.d.). Of baptism. Retrieved November 22, 2019, from monergism.com website: https://www.monergism.com/baptis $\mathrm{m}-0$ 